\title{
Postnatal nutritional restriction affects growth and immune function of piglets with intra-uterine growth restriction
}

\author{
Liang Hut, Yan Liu†, Chuan Yan, Xie Peng, Qin Xu, Yue Xuan, Fei Han, Gang Tian, Zhengfeng Fang, \\ Yan Lin, Shengyu Xu, Keying Zhang, Daiwen Chen, De Wu and Lianqiang Che* \\ Institute of Animal Nutrition, Sichuan Agricultural University, No. 211, Huimin Road, Wenjiang District, Chengdu, \\ Sichuan 611130, People's Republic of China
}

(Submitted 4 August 2014 - Final revision received 24 February 2015 - Accepted 10 April 2015 - First published online 10 June 2015)

\section{Abstract}

Postnatal rapid growth by excess intake of nutrients has been associated with an increased susceptibility to diseases in neonates with intrauterine growth restricted (IUGR). The aim of the present study was to determine whether postnatal nutritional restriction could improve intestinal development and immune function of neonates with IUGR using piglets as model. A total of twelve pairs of normal-birth weight (NBW) and IUGR piglets ( $7 \mathrm{~d}$ old) were randomly assigned to receive adequate nutrient intake or restricted nutrient intake (RNI) by artificially liquid feeding for a period of $21 \mathrm{~d}$. Blood samples and intestinal tissues were collected at necropsy and were analysed for morphology, digestive enzyme activities, immune cells and expression of innate immunity-related genes. The results indicated that both IUGR and postnatal nutritional restriction delayed the growth rate during the sucking period. Irrespective of nutrient intake, piglets with IUGR had a significantly lower villous height and crypt depth in the ileum than the NBW piglets. Moreover, IUGR decreased alkaline phosphatase activity while enhanced lactase activity in the jejunum and mRNA expressions of Toll-like receptor 9 (TLR-9) and DNA methyltransferase 1 (DNMT1) in the ileum of piglets. Irrespective of body weight, RNI significantly decreased the number and/or percentage of peripheral leucocytes, lymphocytes and monocytes of piglets, whereas the percentage of neutrophils and the ratio of $\mathrm{CD} 4^{+}$to $\mathrm{CD} 8^{+}$were increased. Furthermore, RNI markedly enhanced the mRNA expression of TLR-9 and DNMT1, but decreased the expression of NOD2 and TRAF-6 in the ileum of piglets. In summary, postnatal nutritional restriction led to abnormal cellular and innate immune response, as well as delayed the growth and intestinal development of IUGR piglets.

\section{Key words: Birth weight: Nutritional intake: Innate immunity: Intestine}

Intra-uterine growth restriction (IUGR) is defined as impaired growth and development of the embryo and/or its organs during gestation $^{(1)}$. Approximately $5-10 \%$ of human neonates and $15-20 \%$ of piglets suffer from IUGR, which has been a common problem in human health and animal production ${ }^{(1,2)}$. Neonates with IUGR have been found to have increased morbidity and mortality during the early life period, and have been associated with long-term effects on the risk of adultonset diseases ${ }^{(3,4)}$. Because of IUGR, the development and function of immune system is impaired in neonates ${ }^{(5)}$. Also, IUGR has been found to cause immunodeficiency and increased vulnerability to infectious diseases in later life ${ }^{(6-8)}$. In animal models, poor proliferation of lymphocytes in thymus and decreasing cytokine levels in peripheral blood had been observed in rats and sheep with $\operatorname{IUGR}^{(9,10)}$.

Neonates with IUGR are generally fed high nutritional diet to achieve rapid growth, which predisposes to postnatal metabolic syndrome such as obesity, diabetes and CVD ${ }^{(11-13)}$. Furthermore, the recent study has demonstrated that high nutrient intake could impair systematic and intestinal innate immunity of piglets with IUGR ${ }^{(14)}$. In contrast, postnatal milk restriction by cross-fostering feeding was able to protect rats with IUGR from the metabolic syndrome ${ }^{(15,16)}$. In addition, the low nutrient density has been shown to be beneficial for the immune system of broilers ${ }^{(17)}$ and primates ${ }^{(18)}$, probably by enhancing antioxidant capability and T-lymphocyte response ${ }^{(19)}$.

Gastrointestinal tract is the major location for digestion and absorption of nutrients, and the gut-associated lymphoid tissue is the largest immune organ in the body ${ }^{(20)}$. In the present study, therefore, we investigated the effects of postnatal nutritional restriction on systematic and intestinal immune function of piglets with IUGR. Because of the structural and physiological similarities of gastrointestinal tract between pigs and human beings, pigs have been recognised as an

\footnotetext{
Abbreviations: ANI, adequate nutrient intake; AP, alkaline phosphatase; BW, body weight; IUGR, intra-uterine growth restriction; NBW, normal-birth weight; RNI, restricted nutrient intake; VCR, villi:crypt ratio.
}

*Corresponding author: Associate Professor L. Che, fax +86 28 86291256; email clianqiang@hotmail.com

†L. H. and Y. L. contributed equally to this article. 
ideal model for the study of clinical nutrition ${ }^{(21,22)}$. As a multifetal domestic animal, pigs have exhibited severe naturally occurring IUGR due to utero-placental insufficiency ${ }^{(21)}$.

\section{Materials and methods}

\section{Animal care and formula milk}

The experiment followed the actual law of animal protection and was approved by the Animal Care and Use Committee of the Sichuan Agricultural University, and was performed in accordance with the National Research Council's Guide for the Care and Use of Laboratory Animals. The basic formula milk powder (Table 1) was formulated according to our previous studies ${ }^{(14)}$. The basic nutrient-level formula milk was prepared by mixing $1 \mathrm{~kg}$ of formula milk powder (DM $87 \cdot 5 \%$ ) with 4 litres of water to a milk solution, which was prepared to supply the same amount of nutrient as sow milk.

\section{Postnatal nutritional restriction model}

A total of twelve pairs of newborn boars (Pig Improvement Company $327 \times 1050)$ of normal-birth weight $(\mathrm{NBW})$ with a body weight (BW) of 1.56 (SD 0.05) kg and IUGR with a BW of 0.91 (SD 0.03$) \mathrm{kg}$ from twelve healthy sows with the same litter size (ten piglets/litter) were chosen according to the previous studies $^{(23)}$. All piglets were weaned at $7 \mathrm{~d}$ of age, and were moved to be individually fed with formula milk per

Table 1. Composition and nutrient level of the basal formula milk powder (87.5\% DM basis, \%)

\begin{tabular}{lc}
\hline Ingredients & $\%$ \\
\hline Whole-milk powder (24\% CP) & $58 \cdot 00$ \\
Whey protein concentrate (34\% CP) & $25 \cdot 00$ \\
Casein & $5 \cdot 70$ \\
Coconut oil & $10 \cdot 00$ \\
CaH $_{2}$ PO & \\
Choline chloride (50\%) & $0 \cdot 10$ \\
Vitamin premix* & $0 \cdot 10$ \\
Mineral premix† & 0.10 \\
L-Arg (98.5\%) & 0.50 \\
DL-Met (98.5\%) & 0.06 \\
L-Lys.HCl (78.5\%) & 0.06 \\
L-Thr (98\%) & \\
L-Trp (98\%) & 0.03 \\
Total & 0.05 \\
Nutrient content & 100.00 \\
Digestible energy (kJ/kg) & \\
CP (\%) & 18390 \\
Ca (\%) & 25.30 \\
Total P (\%) & 1.02 \\
Available P (\%) & 0.81 \\
Digestible Lys (\%) & 0.67 \\
Digestible Met (\%) & 1.93 \\
Digestible Arg (\%) & 0.63 \\
\hline
\end{tabular}

$\mathrm{CP}$, crude protein.

${ }^{*}$ Vitamin premix provided per $\mathrm{kg}$ powder diet: vitamin $\mathrm{A}, 0.94 \mathrm{mg}$; vitamin $\mathrm{D}_{3}$ $0.01 \mathrm{mg}$; vitamin $\mathrm{E}, 20 \mathrm{mg}$; vitamin $\mathrm{K}_{3}, 1 \mathrm{mg}$; vitamin $\mathrm{B}_{12}, 0.04 \mathrm{mg}$; riboflavin $5 \mathrm{mg}$; niacin, $20 \mathrm{mg}$; pantothenic acid, $15 \mathrm{mg}$; folic acid, $1.5 \mathrm{mg}$; thiamin, $1.5 \mathrm{mg}$; pyridoxine, $2 \mathrm{mg}$; biotin, $0.1 \mathrm{mg}$.

† Mineral premix provided per kg powder diet: Zn, $90 \mathrm{mg}$; Mn, $4.0 \mathrm{mg} ; \mathrm{Fe}, 90 \mathrm{mg}$ $\mathrm{Cu}, 6.0 \mathrm{mg} ; \mathrm{I}, 0.2 \mathrm{mg} ; \mathrm{Se}, 0.3 \mathrm{mg}$. meal every $3 \mathrm{~h}$ by bottle feeding between 06.00 and 24.00 hours in nursing cages $(0.8 \mathrm{~m} \times 0.7 \mathrm{~m} \times 0.4 \mathrm{~m})$. For nutritional treatments, six pairs of NBW and IUGR piglets were randomly assigned to have adequate nutrient intake (ANI) and the other six pairs were allocated to have restricted nutrient intake (RNI) in pairs. Thus, in total, four groups (birth weight-nutrient intake) of male piglets were created and studied: NBW-ANI; IUGR-ANI; NBW-RNI; IUGR-RNI ( $n$ 6). Among them, NBWANI and IUGR-ANI piglets had formula milk ad libitum, NBW-RNI piglets were provided the same amount of formula milk as IUGR-ANI piglets, while IUGR-RNI piglets were provided approximately $70 \%$ of formula milk intake by IUGR-ANI pigs (Table 3). All piglets had free access to drinking-water. Room temperature was maintained at approximately $30^{\circ} \mathrm{C}$, and humidity was controlled between 50 and $60 \%$. BW and formula milk intake of piglets were recorded daily. The average daily DM intake was calculated via multiplying the average daily intake of formula milk by its DM content (\%), while formula milk intake was calculated as the difference between the offered amounts and the refusals.

\section{Blood sampling and analyses}

Blood samples were collected by venepuncture on the morning (08.00 hours) of day 21 after an overnight fast, and were injected into two vacuum tubes containing sodium heparin. The vacuum tubes were immediately placed on ice until they arrived at the veterinary hospital for the examination of leucocytes and flow cytometry analysis, respectively (within $2 \mathrm{~h}$ ). Leucocyte examinations (neutrophil, lymphocyte and monocyte counts) were done through an automatic blood analyser. Total peripheral blood lymphocytes were separated from heparinised peripheral blood by separation medium, and were then stained with mouse anti-porcine CD3e-SPRD (PE-Cy5; catalogue no. 4510-13), CD4a-FITC (catalogue no. 4515-02) and CD8a-PE (catalogue no. 4520-09), which were purchased from Southern Biotechnology Associates. PBS $(1 \times$; Gibco) and $1.0 \%$ bovine serum albumin (ICN Biomedicals) were used as diluent and washing buffer. Flow cytometry analysis was performed on a FACSCalibur flow cytometer (Becton Dickinson) and was repeated for the same sample and compared for repeatability.

\section{Tissue sample collection}

Piglets were weighed, and crown-rump length (CRL) was taken (the supine length of the piglet from the crown of its head to the base of its tail) at days 7 and 28. BMI (BW/ $\mathrm{CRL}^{2}$ ) was calculated for each piglet. At day 28, all piglets were anaesthetised with an intravenous injection of sodium pentobarbital $(15 \mathrm{mg} / \mathrm{kg} \mathrm{BW})$ and killed. The liver, spleen, kidney, heart and pancreas of each piglet were weighed immediately. The length and weight of the small intestine were measured after the removal of luminal contents. Duodenal, jejunal and ileal samples of approximately $2 \mathrm{~cm}$ in length were stored in $4 \%$ paraformaldehyde solution for histological analyses. The rest of the ileum was snap-frozen and then stored at $-80^{\circ} \mathrm{C}$ until further analysis. 


\section{Small intestinal morphology and goblet cell counting}

The duodenal, jejunal and ileal samples were preserved in $4 \%$ paraformaldehyde solution and then embedded in paraffin. Each sample (duodenum, jejunum and ileum) was used to prepare five slides, and each slide had three sections $(5 \mu \mathrm{m}$ thickness), which were stained with eosin and haematoxylin for intestinal morphology measurement by twenty welloriented villi and crypts each section (Optimus software version 6.5; Media Cybergenetics), and villi:crypt ratio (VCR) was calculated. The goblet cell number per villus was measured (NIS-Elements BR 2.3; Nikon France SAS). The values obtained from ten villi from each small intestinal segment per piglet were averaged.

\section{Enzyme analyses}

After thawing, the frozen jejunal sample was weighed and homogenised $(5 \mathrm{~min})$ in the nine times volume of $50 \mathrm{~mm}$ Tris-HCl buffer, $\mathrm{pH} 7 \cdot 0$, centrifuged $(3000 \mathrm{~g}, 10 \mathrm{~min})$, and the supernatant was collected and stored at $-20^{\circ} \mathrm{C}$ for the enzyme assay. Total proteins were extracted, and their concentration was determined according to the procedure of bicinchoninic acid (Solarbio, Inc.), with bovine serum albumin as the standard. Disaccharidase (including maltase, sucrase and lactase) and alkaline phosphatase (AP) were measured using commercial kits (Nanjing Jiancheng Bioengineering Institute) according to the manufacturer's instructions.

Table 2. Primer sequences of the target and reference genes
The absorbance was determined with spectrophotometer (Beckman Coulter DU-800; Beckman Coulter, Inc.). The activities of disaccharidases were presented as $\mathrm{U} / \mathrm{mg}$ protein, while the AP activity was presented as U/g protein. One unit (U) was defined as $1 \mathrm{nmol}$ maltose, sucrose, lactose or AP as substrate for the enzymatic reaction.

\section{Total RNA extraction and real-time RT-PCR}

Total RNA was extracted from frozen placenta using TRIzol Reagent (catalogue no. 15596-026; Invitrogen) according to the manufacturer's instructions. The quality and purity of RNA samples were assessed by electrophoresis on $1.0 \%$ agarose gel and nucleic acid analyser (A260/A280, Beckman DU-800; Beckman Coulter, Inc.), respectively. Subsequently, the RNA was performed at $37^{\circ} \mathrm{C}$ for $15 \mathrm{~min}$, followed by RT inactivation at $85^{\circ} \mathrm{C}$ for $5 \mathrm{~s}$ using PrimeScript ${ }^{\mathrm{TM}} \mathrm{RT}$ reagent Kit (catalogue no. RR047A; Takara). A $1 \mu$ l portion of the RT products was used directly for real-time PCR. Real-time PCR was performed on ABI-7900HT instrument (Applied Biosystems). Oligonucleotide primers were used to detect the gene expressions of the target gene and the reference gene ( $\beta$-actin) using the SYBR green system (catalogue no. RR820A; Takara). The sequences of primers and length of the products were presented in Table 2. The reaction mixture $(10 \mu \mathrm{l})$ contained $5 \mu \mathrm{l}$ of fresh $\mathrm{SYBR}^{\circledR}$ Premix Ex TaqII (Tli RNaseH Plus) and $0 \cdot 2 \mu$ l ROX Reference Dye II $(50 \times), 0 \cdot 8 \mu$ l of the primers, $1 \mu \mathrm{l}$ of RT products and

\begin{tabular}{|c|c|c|c|}
\hline Genes & Primer sequence $\left(5^{\prime}-3^{\prime}\right)$ & Product (bp) & GenBank accession \\
\hline TLR-2 & $\begin{array}{l}\text { Forward: TCGAAAAGAGCCAGAAAACCAT } \\
\text { Reverse: CTTGCACCACTCGCTCTTCA }\end{array}$ & 58 & NM213761 \\
\hline$T L R-4$ & $\begin{array}{l}\text { Forward: AGAAAATATGGCAGAGGTGAAAGC } \\
\text { Reverse: CTTCGTCCTGGCTGGAGTAGA }\end{array}$ & 64 & GQ304754 \\
\hline$T L R-9$ & $\begin{array}{l}\text { Forward: AATCCAGTCGGAGATGTTTGGT } \\
\text { Reverse: GACCGCCTGGGAGATGCT }\end{array}$ & 79 & AY859728 \\
\hline MyD88 & $\begin{array}{l}\text { Forward: GTGCCGTCGGATGGTAGTG } \\
\text { Reverse: TCTGGAAGTCACATTCCTTGCTT }\end{array}$ & 65 & NM001099923 \\
\hline TRAF-6 & $\begin{array}{l}\text { Forward: GCTGCATCTATGGCATTTGAAG } \\
\text { Reverse: CCACAGATAACATTTGCCAAAGG }\end{array}$ & 70 & AJ606305.1 \\
\hline$N F-\kappa B 1$ & $\begin{array}{l}\text { Forward: AGGATGGGATCTGCACTGTC } \\
\text { Reverse: TCTGTCATTCGTGCTTCCAG }\end{array}$ & 121 & DQ834921.1 \\
\hline SIGIRR & $\begin{array}{l}\text { Forward: ACCTGGGCTCCCGAAACTAC } \\
\text { Reverse: GTCATCTTCTGACACCAGGCAAT }\end{array}$ & 62 & AK239384.1 \\
\hline TOLLIP & $\begin{array}{l}\text { Forward: CCCGCGCTGGAATAAGG } \\
\text { Reverse: CATCAAAGATCTCCAGGTAGAAGGA }\end{array}$ & 74 & AK239879.1 \\
\hline$I L-1 \beta$ & $\begin{array}{l}\text { Forward: TCTGCCCTGTACCCCAACTG } \\
\text { Reverse: CCAGGAAGACGGGCTTTTG }\end{array}$ & 64 & NM214055.1 \\
\hline$\beta$-Actin & $\begin{array}{l}\text { Forward: GGCGCCCAGCACGAT } \\
\text { Reverse: CGATCCACACGGAGTACTTG }\end{array}$ & 66 & DQ845171.1 \\
\hline IL-6 & $\begin{array}{l}\text { Forward: GATGCTTCCAATCTGGGTTCA } \\
\text { Reverse: CACAAGACCGGTGGTGATTCT }\end{array}$ & 62 & M80258.1 \\
\hline NOD2 & $\begin{array}{l}\text { Forward: CCGAGCGCATCCTCTTAA } \\
\text { Reverse: GACGCTCGTGATCCGTGAA }\end{array}$ & 70 & AB195466.1 \\
\hline DNMT1 & $\begin{array}{l}\text { Forward: AGGTGAGGACATGCAGCTTT } \\
\text { Reverse: AACTTGTTGTCCTCCGTTGG }\end{array}$ & 68 & DQ060156.1 \\
\hline DNMT3A & $\begin{array}{l}\text { Forward: TGCCAAAACTGCAAGAACTG } \\
\text { Reverse: CAGCAGATGGTGCAGTAGGA }\end{array}$ & 83 & NM_001097437.1 \\
\hline DNMT3B & $\begin{array}{l}\text { Forward: AATCGCAACAGGGTACTTGG } \\
\text { Reverse: GGTTCCAACAGCAATGGACT }\end{array}$ & 97 & NM_001162404.1 \\
\hline
\end{tabular}

TLR, Toll-like receptor; MyD88, myeloid differentiation factor 88; TRAF-6, TNF receptor-associated factor 6; SIGIRR, single Ig IL-1-related receptor; TOLLIP, Toll-interacting protein; NOD2, nucleotide-binding oligomerisation domain 2; DNMT, DNA methyltransferase. 
$3 \mu \mathrm{l}$ of diethylpyrocarbonate-treated water. The following PCR protocol was used: one cycle $\left(95^{\circ} \mathrm{C} 30 \mathrm{~s}\right)$; forty cycles $\left(95^{\circ} \mathrm{C} 5 \mathrm{~s}\right.$, $\left.60^{\circ} \mathrm{C} 31 \mathrm{~s}\right)$; one cycle $\left(95^{\circ} \mathrm{C} 15 \mathrm{~s}, 60^{\circ} \mathrm{C} 1 \mathrm{~min}\right.$ and $95^{\circ} \mathrm{C} 15 \mathrm{~s}$ ). The standard curve of each gene was run in duplicate and three times for obtaining reliable amplification efficiency values as described previously ${ }^{(24)}$. The correlation coefficients $(r)$ of all the standard curves were $>0.99$, and the amplification efficiency values were between 90 and $110 \%$. At the end of amplification, melting curve analysis was performed to identify amplification specificity. $\beta$-Actin transcript was used to standardise the results by eliminating variations in mRNA and complementary DNA quantity and quality, and each mRNA level was expressed as its ratio to $\beta$-actin mRNA. The relative quantification of gene expression among the treatment groups was analysed by the $2^{-\Delta \Delta C_{\mathrm{t}}} \operatorname{method}^{(25)}$.

\section{Statistical analysis}

Results are presented as means with their standard errors. Data of intestinal morphology were analysed as repeated measures using the MIXED procedure of Statistical Product and Service Solutions 20.0 (SPSS, Inc.) according to the following model:

$$
\begin{aligned}
Y_{i j k l}= & \mu+\alpha_{i}+\beta_{j}+(\alpha \beta)_{i j}+U_{k}+\omega_{l}+(\alpha \omega)_{i l}+(\beta \omega)_{j l} \\
& +(\alpha \beta \omega)_{i j l}+\epsilon_{i j k l},
\end{aligned}
$$

where $Y_{i j k l}$ represents the dependent variable, $\mu$ is the mean, $\alpha_{i}$ is the effect of BW ( $i=$ IUGR, NBW), $\beta_{j}$ is the effect of NI ( $j=$ ANI, RNI), $(\alpha \beta)_{i j}$ is the interaction between BW and NI, $U_{k} \sim N\left(0, \sigma^{2}\right)$ is the litter $(k=1,2, \ldots, 12), \omega_{l}$ is the segment (duodenum, jejunum and ileum), $(\alpha \omega)_{i l}$ refers to the interaction between BW and segment, $(\beta \omega)_{j l}$ refers to the (IUGR) and normal-birth weight (NBW) neonates

(Mean values with their standard errors) interaction between NI and segment, $(\alpha \beta \omega)_{i j l}$ refers to the interaction between BW, NI and segment, and $\boldsymbol{\epsilon}_{i j k l}$ represents the error term. Data on growth performance, organ indices, blood leucocytes, lymphocyte percentages, enzyme activities and gene expressions were analysed according to the model, but omitting the effect of segment and the interaction between segment, BW and NI. Differences between groups were also analysed using general linear model procedure followed by Duncan's test. $P<0.05$ was considered as statistically significant.

\section{Results}

\section{Growth performance}

In the present study, IUGR piglets had lower BW (-33-38\%, $P<0.001)$ and shorter CRL $(-10-17 \%, P<0.001)$ than NBW piglets, and these differences persisted until 4 weeks of age (Table 3). Regardless of BW, RNI markedly decreased the net weight gain $(-25 \%, P=0.002)$, average daily gain $(-26 \%, P=0.002)$ and average daily DM intake $(-29 \%$, $P<0.001)$ of piglets; however, no difference in feed conversion ratio was observed. Throughout the experimental period, moreover, there was similar average daily gain and net weight gain between the IUGR-ANI and the NBW-RNI piglets due to their similar average daily DM intake and feed conversion ratio.

\section{Organ indices}

Regardless of NI, weights of internal organs such as intestine, heart, liver, spleen, kidney, brain and pancreas were markedly

\begin{tabular}{|c|c|c|c|c|c|c|c|c|}
\hline \multirow[b]{2}{*}{ Parameters } & \multicolumn{2}{|c|}{ ANI } & \multicolumn{2}{|c|}{ RNI } & \multirow[b]{2}{*}{ SEM } & \multicolumn{3}{|c|}{$P$} \\
\hline & NBW & IUGR & NBW & IUGR & & BW & $\mathrm{NI}$ & $\mathrm{BW} \times \mathrm{NI}$ \\
\hline Initial weight (kg) & $2 \cdot 92^{b}$ & $1 \cdot 80^{\mathrm{a}}$ & $2 \cdot 91^{\mathrm{b}}$ & $1 \cdot 81^{\mathrm{a}}$ & 0.16 & $<0.001$ & 0.976 & 0.904 \\
\hline Day 7 CRL (cm) & $34^{\mathrm{b}}$ & $29^{\mathrm{a}}$ & $35^{\mathrm{b}}$ & $28^{\mathrm{a}}$ & 1 & $<0.001$ & 0.874 & 0.084 \\
\hline Final weight (kg) & $8 \cdot 23^{d}$ & $5 \cdot 57^{b}$ & $6 \cdot 88^{\mathrm{c}}$ & $4 \cdot 60^{\mathrm{a}}$ & 0.71 & $<0.001$ & 0.006 & 0.720 \\
\hline Day 28 CRL (cm) & $50^{\mathrm{b}}$ & $46^{\mathrm{a}}$ & $51^{\mathrm{b}}$ & $44^{\mathrm{a}}$ & 2 & $<0.001$ & 0.663 & 0.178 \\
\hline Net weight gain $(\mathrm{kg})$ & $5 \cdot 31^{c}$ & $3.76^{\mathrm{b}}$ & $3.96^{\mathrm{b}}$ & $2 \cdot 82^{\mathrm{a}}$ & 0.60 & $<0.001$ & 0.002 & 0.713 \\
\hline \multicolumn{9}{|l|}{$A D G(g / d)$} \\
\hline Days $0-7$ & $101^{\mathrm{b}}$ & $69^{\mathrm{a}}$ & $68^{\mathrm{a}}$ & $50^{\mathrm{a}}$ & 19 & 0.007 & 0.016 & 0.151 \\
\hline Days $7-14$ & $275^{\mathrm{b}}$ & $160^{\mathrm{a}}$ & $171^{\mathrm{a}}$ & $115^{\mathrm{a}}$ & 47 & $<0.001$ & 0.004 & 0.122 \\
\hline Days $14-21$ & $361^{\mathrm{c}}$ & $294^{\mathrm{b}}$ & $309^{b}$ & $222^{\mathrm{a}}$ & 56 & 0.005 & 0.058 & 0.745 \\
\hline Days $0-21$ & $253^{c}$ & $180^{\mathrm{b}}$ & $189^{b}$ & $133^{a}$ & 30 & $<0.001$ & 0.002 & 0.352 \\
\hline \multicolumn{9}{|l|}{ ADMI (g/d) } \\
\hline Days $0-7$ & $97^{c}$ & $60^{a, b}$ & $76^{\mathrm{b}, \mathrm{c}}$ & $48^{a}$ & 13 & $<0.001$ & 0.040 & 0.562 \\
\hline Days $7-14$ & $212^{b}$ & $130^{\mathrm{a}}$ & $131^{\mathrm{a}}$ & $86^{a}$ & 25 & $<0.001$ & $<0.001$ & 0.228 \\
\hline Days $14-21$ & $280^{\mathrm{C}}$ & $216^{b}$ & $212^{b}$ & $151^{\mathrm{a}}$ & 22 & $<0.001$ & $<0.001$ & 0.916 \\
\hline Days $0-21$ & $201^{c}$ & $139^{b}$ & $143^{b}$ & $97^{\mathrm{a}}$ & 17 & $<0.001$ & $<0.001$ & 0.398 \\
\hline \multicolumn{9}{|l|}{$\mathrm{FCR}^{*}$} \\
\hline Days 0-7 & 0.98 & 0.88 & $1 \cdot 12$ & 0.99 & $0 \cdot 16$ & $0 \cdot 170$ & 0.115 & 0.862 \\
\hline Days 7-14 & 0.78 & 0.83 & 0.79 & 0.77 & $0 \cdot 11$ & 0.746 & 0.697 & 0.490 \\
\hline Days $14-21$ & 0.84 & 0.74 & 0.69 & 0.69 & $0 \cdot 11$ & 0.420 & 0.143 & 0.441 \\
\hline Days $0-21$ & 0.80 & 0.78 & 0.76 & 0.74 & 0.05 & 0.416 & 0.139 & 0.979 \\
\hline
\end{tabular}

Table 3. Effects of the level of nutrient intake $(\mathrm{NI})$ on the growth performance of intra-uterine growth restricted

ANI, adequate nutrient intake; RNI, restricted nutrient intake; BW, body weight; CRL, crown-rump length; ADG, average daily gain; ADMI, average daily DM intake; FCR, feed conversion ratio.

a,b,c,d Mean values within a row with unlike superscript letters were significantly different $(P<0.05)$.

${ }^{*}$ FCR was calculated by dividing the ADMI by its corresponding ADG. 
decreased $(-7-33 \%, P<0 \cdot 010)$ in IUGR relative to NBW piglets (Table 4). However, the relative intestinal length, heart and brain weights to BW were significantly higher $(+21-$ $41 \%, P<0.050)$ in IUGR relative to NBW piglets. Meanwhile, BMI values at both days 7 and 28 were significantly decreased by IUGR $(-11-19 \%, P<0.001)$ relative to NBW piglets. Regardless of BW, moreover, the weights of heart $(P=0.019)$, liver $(P=0 \cdot 010)$ and kidney $(P=0 \cdot 014)$ were markedly reduced by RNI, while NI and BW had significant interaction on the weight of heart $(P=0 \cdot 003)$.

\section{Composition of peripheral leucocytes and lymphocyte percentages}

In Fig. 1, regardless of BW, the counts of leucocytes, lymphocytes and monocytes were significantly decreased $(-20-45 \%$, $P<0.010)$ by RNI. Moreover, the percentage of lymphocytes decreased $(P=0.028)$ while the percentage of neutrophils increased $(P=0.036)$ by RNI. In addition, IUGR-RNI piglets had lower counts of leucocytes and lymphocytes $(P<0 \cdot 050)$ than IUGR-ANI piglets, respectively. The percentage of $\mathrm{CD}^{+} \mathrm{T}$ cells had the tendency to decrease $(P=0.083)$ by RNI, resulting in the increased $(P=0.034)$ ratio of $\mathrm{CD}_{4}^{+}$to $\mathrm{CD}^{+}$(Fig. 2(D)). Furthermore, the percentage of $\mathrm{CD}^{+}$of IUGR-RNI piglets was lower $(P<0.050)$ than that in IUGRANI piglets (Fig. 2(C)).

\section{Intestinal morphology and goblet cell density}

BW and NI had a significant interaction effect on villous height $(P=0.001)$ and the VCR $(P<0.001)$. The villous height
$(P<0.001)$, the crypt depth $(P<0.001)$ and the VCR $(P<0.035)$ were significantly affected by the segment in the small intestine, with the duodenum having the highest villous height and the deepest crypt depth and the jejunum having the highest VCR (Table 5). Moreover, the density of the total goblet cells per intestinal villus of the IUGR-RNI piglets was higher $(P<0.050)$ than that of the IUGR-ANI piglets in the small intestine (Table 6)

\section{Jejunal enzyme activities}

Irrespective of NI, the activity of jejunal AP was markedly lower $(P=0.028)$, while the activity of lactase was markedly higher $(P=0.046)$ in IUGR piglets relative to NBW piglets (Table 7). Furthermore, IUGR-RNI piglets had similar AP activity as NBW-RNI piglets, while it was much lower in IUGR-ANI piglets relative to NBW-ANI piglets $(P<0 \cdot 050)$.

\section{Gene expression in the ileum}

Regardless of NI, the mRNA abundance of Toll-like receptor 9 (TLR-9) was markedly increased $(P=0.030)$, and DNA methyltransferase 1 (DNMT1) tended to increase $(P=0.070)$ in the ileum of IUGR piglets relative to NBW piglets. Regardless of BW, moreover, the mRNA abundance of TLR-9 and DNMT1 was significantly higher $(P<0 \cdot 010)$, while the mRNA abundance of TNF receptor-associated factor 6 (TRAF- 6$)$ and nucleotide-binding oligomerisation domain 2 (NOD2) was significantly lower $(P<0 \cdot 010)$ in the ileum tissues of piglets with RNI than that of piglets with ANI. In addition, the significant interaction between BW and NI was observed for the mRNA abundance of DNMT1 ( $P=0 \cdot 007)$ in the ileum (Fig. 3).

Table 4. Effects of the level of nutrient intake ( $\mathrm{NI}$ ) on the organ indices of intra-uterine growth restricted (IUGR) and normal-birth weight (NBW) neonates

(Mean values with their standard errors)

\begin{tabular}{|c|c|c|c|c|c|c|c|c|}
\hline \multirow[b]{2}{*}{ Parameters } & \multicolumn{2}{|c|}{ ANI } & \multicolumn{2}{|c|}{$\mathrm{RNI}$} & \multirow[b]{2}{*}{ SEM } & \multicolumn{3}{|c|}{$P$} \\
\hline & NBW & IUGR & NBW & IUGR & & BW & $\mathrm{NI}$ & $\mathrm{BW} \times \mathrm{NI}$ \\
\hline Intestinal L (cm) & $815^{\mathrm{c}}$ & $644^{a, b}$ & $728^{\mathrm{b}, \mathrm{c}}$ & $590^{a}$ & 87 & $<0.001$ & 0.074 & 0.670 \\
\hline Intestinal wt (g) & $492^{\mathrm{b}}$ & $356^{\mathrm{a}}$ & $495^{\mathrm{b}}$ & $312^{\mathrm{a}}$ & 67 & $<0.001$ & 0.523 & 0.457 \\
\hline Heart wt $(g)$ & $48^{\mathrm{b}}$ & $32^{\mathrm{a}}$ & $39^{\mathrm{a}}$ & $34^{\mathrm{a}}$ & 4 & $<0.001$ & 0.019 & 0.003 \\
\hline Liver wt (g) & $215^{\mathrm{c}}$ & $141^{\mathrm{a}}$ & $174^{\mathrm{b}}$ & $120^{\mathrm{a}}$ & 20 & $<0.001$ & 0.010 & 0.359 \\
\hline Spleen wt (g) & $14.9^{\mathrm{b}}$ & $9 \cdot 8^{\mathrm{a}}$ & $13 \cdot 1^{\mathrm{b}}$ & $9 \cdot 3^{\mathrm{a}}$ & $1 \cdot 8$ & $<0.001$ & 0.189 & 0.455 \\
\hline Kidney wt (g) & $28^{\mathrm{c}}$ & $19^{b}$ & $23^{b}$ & $16^{\mathrm{a}}$ & 3 & $<0.001$ & 0.014 & 0.573 \\
\hline Brain wt $(\mathrm{g})$ & $51^{\mathrm{b}}$ & $46^{a}$ & $49^{b}$ & $46^{\mathrm{a}}$ & 3 & 0.006 & 0.599 & 0.475 \\
\hline Pancreas wt (g) & $13 \cdot 5^{\mathrm{C}}$ & $9 \cdot 9^{\mathrm{a}, \mathrm{b}}$ & $11 \cdot 4^{\mathrm{b}, \mathrm{c}}$ & $8 \cdot 8^{\mathrm{a}}$ & 1.7 & 0.001 & 0.132 & 0.792 \\
\hline Dissected organs wt (g) & $817^{b}$ & $619^{a}$ & $803^{b}$ & $544^{\mathrm{a}}$ & 69 & $<0.001$ & 0.175 & 0.353 \\
\hline Intestinal wt:BW (\%) & 6.06 & 6.94 & $6 \cdot 74$ & 6.98 & 0.67 & 0.091 & 0.265 & 0.312 \\
\hline Intestinal L:BW (cm/kg) & $102^{\mathrm{a}}$ & $124^{\mathrm{b}, \mathrm{c}}$ & $108^{a, b}$ & $131^{\mathrm{c}}$ & 11 & $<0.001$ & 0.129 & 0.754 \\
\hline Liver wt:BW (\%) & $2 \cdot 70$ & $2 \cdot 80$ & 2.68 & $2 \cdot 68$ & 0.41 & 0.810 & 0.702 & 0.923 \\
\hline Spleen wt:BW (\%) & $0 \cdot 19$ & 0.20 & $0 \cdot 19$ & 0.21 & 0.02 & 0.244 & 0.401 & 0.866 \\
\hline Kidney wt:BW (\%) & 0.35 & 0.39 & 0.34 & 0.35 & 0.04 & 0.172 & 0.145 & 0.385 \\
\hline Heart wt:BW (\%) & $0.57^{\mathrm{a}}$ & $0.64^{a, b}$ & $0.58^{a}$ & $0.77^{\mathrm{b}}$ & 0.08 & 0.025 & 0.191 & 0.216 \\
\hline Pancreas wt:BW (\%) & 0.17 & 0.19 & 0.17 & 0.19 & 0.03 & 0.144 & 0.741 & 0.741 \\
\hline Brain wt:BW (\%) & $0.65^{\mathrm{a}}$ & $0.93^{\mathrm{b}}$ & $0.75^{\mathrm{a}}$ & $1.04^{b}$ & 0.09 & $<0.001$ & 0.033 & 0.944 \\
\hline Day $7 \mathrm{BMI}\left(\mathrm{kg} / \mathrm{m}^{2}\right)$ & $26 \cdot 3^{\mathrm{C}}$ & $21 \cdot 1^{a}$ & $24 \cdot 0^{b, c}$ & $23 \cdot 7^{b}$ & 1.5 & 0.001 & 0.782 & 0.002 \\
\hline Day $28 \mathrm{BMI}\left(\mathrm{kg} / \mathrm{m}^{2}\right)$ & $32 \cdot 3^{\mathrm{b}}$ & $24 \cdot 5^{\mathrm{a}}$ & $26 \cdot 3^{a}$ & $23 \cdot 0^{\mathrm{a}}$ & $2 \cdot 6$ & $<0.001$ & 0.009 & 0.089 \\
\hline
\end{tabular}

$\mathrm{ANI}$, adequate nutrient intake; RNI, restricted nutrient intake; BW, body weight; L, length; wt, weight

${ }_{a, b, c}$ Mean values within a row with unlike superscript letters were significantly different $(P<0.05)$ 

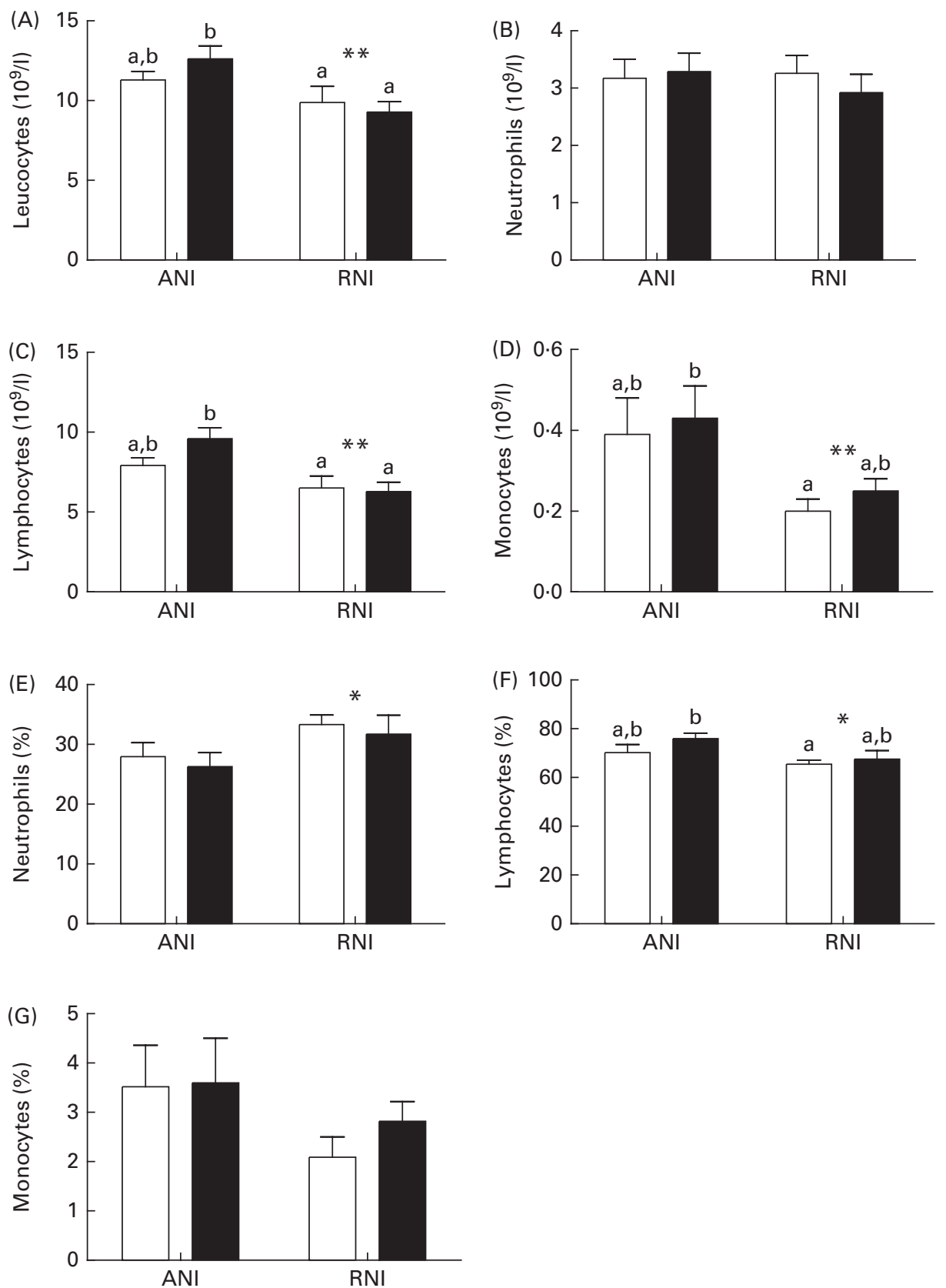

Fig. 1. Effects of the level of nutrient intake on the count and percentage of blood leucocytes (A), neutrophils (B and $E$ ), lymphocytes (C and $F)$ and monocytes $(D$ and $G$ ) in intra-uterine growth restricted $(\square)$ and normal-birth weight $(\square)$ neonates. Values are means, with their standard errors represented by vertical bars. ${ }^{\mathrm{a}, \mathrm{b}}$ Mean values with unlike letters were significantly different $(P<0.05)$. Mean values were significantly different from those of the adequate nutrient intake (ANI) group: ${ }^{*} P<0.05,{ }^{*} P<0.01$ (significant effect of level of nutrient intake). There was no significant interaction between body weight and nutrient intake. RNI, restricted nutrient intake.

\section{Discussion}

Neonates with IUGR have been shown to present immature immune system compared with their normal counterparts ${ }^{(26,27)}$. In the present study, we sought to elucidate the role of postnatal nutritional environment on growth performance and immune function of neonates with IUGR using piglets as model. Interestingly, the results of the present study demonstrated that postnatal nutritional restriction may delay the growth and development of the small intestine, as well as immune response of IUGR piglets through altering intestinal morphology, enzyme activities, composition of peripheral leucocytes and innate immunity-related gene expressions. However, previous studies have reported the improved immune response in low nutrient intake of broilers and primates ${ }^{(17,18)}$; this differential response may be related to the degrees of nutritional restriction, restricted nutrients and species.

In agreement with previous reports ${ }^{(14)}$, piglets with IUGR had lighter BW than NBW piglets at $28 \mathrm{~d}$ of birth, which 

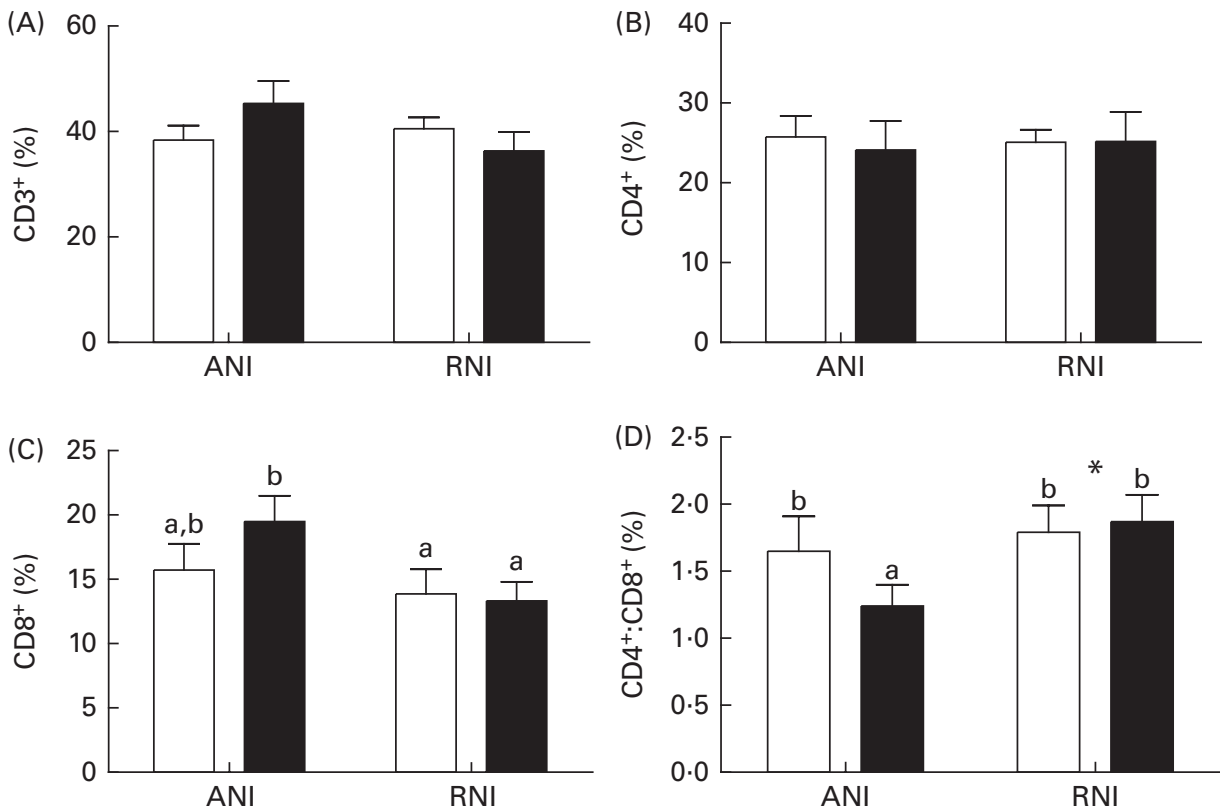

Fig. 2. Effects of the level of nutrient intake on the percentage of $\mathrm{CD}^{+}(\mathrm{A}), \mathrm{CD}^{+}(\mathrm{B}), \mathrm{CD}^{+}(\mathrm{C}) \mathrm{T}^{-l y m p h o c y t e s}$ and the ratio of $\mathrm{CD} 4^{+}$to $\mathrm{CD} 8^{+}(\mathrm{D})$ in intra-uterine growth restricted $(\square)$ and normal-birth weight $(\square)$ neonates. Values are means, with their standard errors represented by vertical bars. ${ }^{a, b}$ Mean values with unlike letters were significantly different $(P<0.05)$. ${ }^{*}$ Mean values were significantly different from those of the adequate nutrient intake $(A N I)$ group $(P<0.05$; significant effect of level of nutrient intake). There was no significant interaction between body weight and nutrient intake. RNI, restricted nutrient intake.

could be resulting from the lower intake of nutrients on day 21 of the suckling period, as indicated by the decreased intake of average daily DM intake in piglets with IUGR. However, the growth rate was similar between IUGR and NBW piglets once they received the same amount of nutrients; however, feed conversion ratio was not markedly different between IUGR and NBW piglets. This finding is consistent with the previous study, which demonstrated that piglets with IUGR had comparable growth response to a high protein diet as NBW piglets $^{(28)}$. In fact, piglets with IUGR have physiological basis for catch-up growth when they are followed by ad libitum milk intake ${ }^{(15)}$.
Along with the smaller body size and weight, piglets with IUGR had lighter relative organ weights than NBW piglets. Consistent with previous results ${ }^{(29)}$, the relative weight of the intestine, heart and brain to BW was markedly increased in piglets with IUGR compared with NBW piglets. These phenotypic changes could be further explained by the programming of 'trade-offs',(30), which selectively allocated maternal nutrition to optimise the growth of internal organs to adapt the chronic placental restriction ${ }^{(31)}$

The small intestine histological analysis could reflect the renewal rate of intestinal epithelial cells. Piglets with IUGR have been shown to have longer and thinner small intestine

Table 5. Effects of the level of nutrient intake (NI) on the intestinal morphology of intra-uterine growth restricted (IUGR) and normal-birth weight (NBW) neonates

(Mean values with their standard errors)

\begin{tabular}{|c|c|c|c|c|c|c|c|c|c|}
\hline \multirow[b]{2}{*}{ Parameters } & \multicolumn{2}{|c|}{ ANI } & \multicolumn{2}{|c|}{$\mathrm{RNI}$} & \multirow[b]{2}{*}{ SEM } & \multicolumn{4}{|c|}{$P$} \\
\hline & NBW & IUGR & NBW & IUGR & & BW & $\mathrm{NI}$ & $\mathrm{BW} \times \mathrm{NI}$ & Segment \\
\hline \multicolumn{10}{|c|}{ Villous height $(\mu \mathrm{m})$} \\
\hline Duodenum & 516 & 445 & 423 & 493 & 72 & 0.978 & 0.333 & 0.001 & $<0.001$ \\
\hline Jejunum & 506 & 430 & 412 & 486 & 93 & & & & \\
\hline Ileum & $439^{b}$ & $369^{a, b}$ & $427^{a, b}$ & $286^{\mathrm{a}}$ & 76 & & & & \\
\hline \multicolumn{10}{|c|}{ Crypt depth $(\mu \mathrm{m})$} \\
\hline Duodenum & 216 & 217 & 208 & 213 & 26 & 0.505 & 0.573 & 0.607 & $<0.001$ \\
\hline Jejunum & 184 & 182 & 188 & 168 & 19 & & & & \\
\hline lleum & 187 & 149 & 220 & 129 & 44 & & & & \\
\hline \multicolumn{10}{|l|}{ VCR } \\
\hline Duodenum & $2 \cdot 39^{b}$ & $2 \cdot 05^{a}$ & $2 \cdot 03^{\mathrm{a}}$ & $2 \cdot 32^{b}$ & 0.24 & 0.555 & 0.832 & $<0.001$ & 0.035 \\
\hline Jejunum & $2 \cdot 76$ & $2 \cdot 34$ & $2 \cdot 19$ & 2.92 & 0.50 & & & & \\
\hline Ileum & $2 \cdot 34$ & $2 \cdot 52$ & 2.05 & $2 \cdot 23$ & 0.36 & & & & \\
\hline
\end{tabular}

$\mathrm{ANI}$, adequate nutrient intake; RNI, restricted nutrient intake; BW, body weight; VCR, villi:crypt ratio.

${ }^{a, b}$ Mean values within a row with unlike superscript letters were significantly different $(P<0.05)$. There was no significant interaction between $\mathrm{NI}$ and Segment. 
Table 6. Effects of the level of nutrient intake $(\mathrm{NI})$ on the density of goblet cells in the small intestine of intra-uterine growth restricted (IUGR) and normal-birth weight (NBW) neonates

(Mean values with their standard errors)

\begin{tabular}{|c|c|c|c|c|c|c|c|c|c|}
\hline \multirow[b]{2}{*}{ Parameters } & \multicolumn{2}{|c|}{ ANI } & \multicolumn{2}{|c|}{$\mathrm{RNI}$} & \multirow[b]{2}{*}{ SEM } & \multicolumn{4}{|c|}{$P$} \\
\hline & NBW & IUGR & NBW & IUGR & & BW & $\mathrm{NI}$ & $\mathrm{BW} \times \mathrm{NI}$ & Segment \\
\hline \multicolumn{10}{|c|}{ Number per villus } \\
\hline Duodenum & $15 \cdot 4^{a, b}$ & $13 \cdot 6^{a}$ & $14 \cdot 5^{a, b}$ & $18 \cdot 6^{b}$ & $2 \cdot 2$ & 0.898 & 0.740 & 0.476 & 0.056 \\
\hline Jejunum & $12 \cdot 9$ & $13 \cdot 2$ & $12 \cdot 7$ & $13 \cdot 0$ & $2 \cdot 7$ & & & & \\
\hline Ileum & 14.9 & $15 \cdot 0$ & $16 \cdot 4$ & $14 \cdot 8$ & $2 \cdot 3$ & & & & \\
\hline
\end{tabular}

ANI, adequate nutrient intake; RNI, restricted nutrient intake; BW, body weight.

${ }^{a, b}$ Mean values within a row with unlike superscript letters were significantly different $(P<0.05)$. There was no significant interaction between NI and Segment.

with reduced villous height relative to NBW piglets ${ }^{(32,33)}$. In the present study, consistently, BW affected intestinal morphology, as indicated by the lower ileum villous height of piglets with IUGR relative to NBW piglets was found. Moreover, there was an interactive effect on intestinal morphology between $\mathrm{BW}$ and NI; nutritional restriction to piglets with IUGR would increase jejunum villous height and VCR. When it comes to distal intestine (ileum), however, RNI tends to decrease villous height of piglets with IUGR. This segmental difference in intestinal morphology might be related to the amount of NI. The proximal intestine had priority to be nursed by nutrition, whereas the distal intestine might be starved with relatively less enteral nutrition in piglets with IUGR-RNI. It has been reported that inadequate enteral nutrition is detrimental for intestinal development ${ }^{(34)}$

Regardless of NI, there were markedly lower villous height and crypt depth in the ileum of piglets with IUGR; accordingly, intestinal activities of AP, which is expressed exclusively in villus-associated enterocytes ${ }^{(35)}$, had been compromised in the jejunum of piglets with IUGR. Because AP has been shown to detoxify lipopolysaccharide and to prevent bacterial invasion across the gut mucosal barrier ${ }^{(35)}$, lower AP activity suggested that intestinal barrier functions may be impaired in the intestine of piglets with IUGR. In the present study, however, the relatively higher lactase activity in piglets with IUGR may be a compensatory response to lack of nutrition supply. The previous study has also shown that survived piglets with IUGR had an enhanced intestinal tropic response to feeding relative to NBW piglets ${ }^{(23)}$. Since lactose is the main component of carbohydrate in milk, higher lactase activity in piglets with IUGR indicated their priority to utilise lactose as energy under the shortage of nutrient ${ }^{(36)}$.
Intestinal epithelial cells could provide an immunological barrier to microbial invasion through both innate and adaptive immune response ${ }^{(37)}$. TLR and Nod-like receptors are two major forms of innate immune sensors ${ }^{(38)}$. TLR are a family of membrane-bound receptors in the activation of innate immunity, whereas Nod-like receptors reside within the cytoplasm to detect microbial motifs that enter into the host cell $^{(39)}$. In the present study, the nutritional restriction to piglets with IUGR markedly up-regulated the intestinal gene expression of TLR-9, but inhibited the gene expression of NOD2 and its downstream molecule (TRAF-O) relative to normal piglets. These findings suggest that nutritional restriction to piglets with IUGR may impair intestinal innate immune response. As a matched nutritional strategy, nutritional restriction has been widely proved to improve the metabolic syndrome of IUGR offspring ${ }^{(40)}$; however, it may not be true when it comes to the evaluation of immunological traits of piglets with IUGR receiving RNI. Moreover, the ileal mRNA level of DNA methyltransferase 1 in piglets with IUGR-RNI was markedly higher than piglets in other groups, which indicates that there may be abnormal DNA methylation, the genomic methylation status has been shown to influence gene expression and recognised as an epigenetic mechanism to link the intra-uterine environment to adult diseases ${ }^{(41)}$.

The immunotype of blood is an important tool in the diagnosis of immunological disorders ${ }^{(42)}$. The cellular immune response of piglets with IUGR to postnatal nutritional restriction is determined by immune cells and lymphocyte subpopulations. In the present study, RNI markedly decreased the number and/or percentage of lymphocytes, leucocytes and monocytes; particularly, RNI disturbed the balance of T-lymphocyte subsets of piglets with IUGR. Similarly, it has been

Table 7. Effects of the level of nutrient intake $(\mathrm{NI})$ on enzyme activities in the jejunum of intra-uterine growth restricted (IUGR) and normal-birth weight (NBW) neonates

(Mean values with their standard errors)

\begin{tabular}{|c|c|c|c|c|c|c|c|c|}
\hline \multirow[b]{2}{*}{ Parameters } & \multicolumn{2}{|c|}{ ANI } & \multicolumn{2}{|c|}{ RNI } & \multirow[b]{2}{*}{ SEM } & \multicolumn{3}{|c|}{$P$} \\
\hline & NBW & IUGR & NBW & IUGR & & BW & $\mathrm{NI}$ & $\mathrm{BW} \times \mathrm{NI}$ \\
\hline AP (U/g protein) & $16 \cdot 64^{b}$ & $13 \cdot 19^{a}$ & $14 \cdot 80^{a, b}$ & $15 \cdot 14^{a, b}$ & 2.05 & 0.028 & 0.393 & 0.280 \\
\hline Lactase (U/mg protein) & 30.44 & 39.43 & $26 \cdot 41$ & $44 \cdot 33$ & $13 \cdot 80$ & 0.046 & 0.835 & 0.734 \\
\hline Maltase (U/mg protein) & $151 \cdot 15$ & $103 \cdot 15$ & 129.08 & 153.09 & 47.89 & 0.545 & 0.482 & 0.079 \\
\hline Sucrase (U/mg protein) & 30.52 & $26 \cdot 76$ & 23.02 & 33.27 & 7.31 & 0.669 & 0.948 & 0.359 \\
\hline
\end{tabular}

$\mathrm{ANI}$, adequate nutrient intake; RNI, restricted nutrient intake; BW, body weight; AP, alkaline phosphatase.

${ }^{\mathrm{a}, \mathrm{b}}$ Mean values within a row with unlike superscript letters were significantly different $(P<0.05)$. 

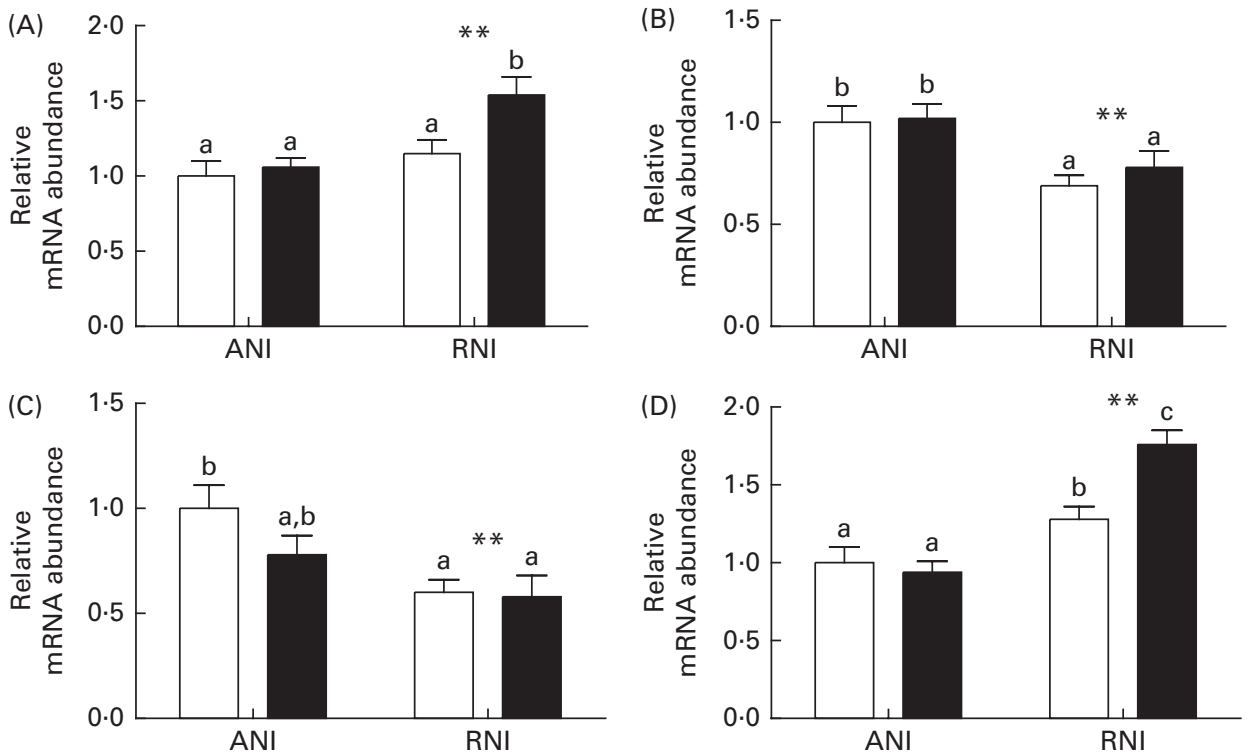

Fig. 3. Effects of the level of nutrient intake on the mRNA abundance of Toll-like receptor 9 (TLR-9) (A), TNF receptor-associated factor 6 (TRAF-6) (B), nucleotide-binding oligomerisation domain 2 (NOD2) (C) and DNA methyltransferase 1 (DNMT1) (D) in the ileum of intra-uterine growth restricted ( $\square$ ) and normal-birth weight $(\square)$ neonates. Values are means, with their standard errors represented by vertical bars. ${ }^{a, b, c}$ Mean values with unlike letters were significantly different $(P<0.05)$. ${ }^{* *}$ Mean values were significantly different from those of the adequate nutrient intake (ANI) group $(P<0.01 ; \operatorname{significant}$ effect of level of nutrient intake). For TLR-9 (A), there was a significant effect of body weight $(P<0.05)$. There was a significant interaction between body weight and nutrient intake on the mRNA abundance of $D N M T 1(P<0.05)$. RNI, restricted nutrient intake.

demonstrated that IUGR leads to the lower lymphocyte counts and alterations in $\mathrm{CD}^{+}$and $\mathrm{CD}^{+}$populations of thymus and spleen in rats ${ }^{(9)}$. The ratio of $\mathrm{CD}^{+}$to $\mathrm{CD}^{+}$has been widely used to determine cellular immune status during disease, nutritional stress and autoimmune problem ${ }^{(43)}$. Neonates with IUGR have been shown to compromise immune system, which may be caused by inadequacy of cell-mediated immune response ${ }^{(5)}$.

In conclusion, postnatal nutritional restriction delayed growth and intestinal development in piglets with IUGR. Most importantly, the present study demonstrated that the immunological traits were abnormal in piglets with IUGR receiving postnatal nutritional restriction. Further investigation is required to determine whether this impact by an early nutrition intervention would persist in adult life.

\section{Acknowledgements}

The present study was supported by the National Natural Science Foundation of China (31101727); the International Cooperation in Science and Technology Project of Sichuan Province (2014HH0034); the Program for Changjiang Scholars and Innovative Research Team in University (IRT13083); and the Natural Science Foundation of Sichuan Province (12ZA110).

The authors' contributions are as follows: L. C. designed the study; L. H., Y. L., C. Y., X. P., Q. X., Y. X., F. H. and G. T. carried out the study; L. H., Z. F., Y. L., S. X., K. Z., D. C. and D. W. performed the analysis and analysed the data; L. H. wrote the paper; L. C. made some modifications in the manuscript.

The authors declare that there are no conflicts of interest.

\section{References}

1. Wu G, Bazer FW, Wallace JM, et al. (2006) Board-invited review: intrauterine growth retardation: implications for the animal sciences. J Anim Sci 84, 2316-2337.

2. McMillen IC \& Robinson JS (2005) Developmental origins of the metabolic syndrome: prediction, plasticity, and programming. Physiol Rev 85, 571-633.

3. Aucott SW, Donohue PK \& Northington FJ (2004) Increased morbidity in severe early intrauterine growth restriction. I Perinatol 24, 435-440.

4. Garite TJ, Clark R \& Thorp JA (2004) Intrauterine growth restriction increases morbidity and mortality among premature neonates. Am J Obstet Gynecol 191, 481-487.

5. Cromi A, Ghezzi F, Raffaelli R, et al. (2009) Ultrasonographic measurement of thymus size in IUGR fetuses: a marker of the fetal immunoendocrine response to malnutrition. Ultrasound Obstet Gynecol 33, 421-426.

6. Raqib R, Alam DS, Sarker P, et al. (2007) Low birth weight is associated with altered immune function in rural Bangladeshi children: a birth cohort study. Am J Clin Nutr 85, 845-852.

7. Manerikar SS, Malaviya AN, Singh MB, et al. (1976) Immune status and BCG vaccination in newborns with intra-uterine growth retardation. Clin Exp Immunol 26, 173-175.

8. Ferguson AC (1978) Prolonged impairment of cellular immunity in children with intrauterine growth retardation. J Pediatr 93, 52-56.

9. Contreras YM, Yu X, Hale MA, et al. (2011) Intrauterine growth restriction alters T-lymphocyte cell number and dual specificity phosphatase 1 levels in the thymus of newborn and juvenile rats. Pediatr Res 70, 123-129.

10. Gao F, Liu Y, Zhang C, et al. (2013) Effect of intrauterine growth restriction during late pregnancy on the growth performance, blood components, immunity and anti-oxidation capability of ovine fetus. Livest Sci 155, 435-441. 
11. Claris O, Beltrand J \& Levy-Marchal C (2010) Consequences of intrauterine growth and early neonatal catch-up growth. Semin Perinatol 34, 207-210.

12. Shahkhalili Y, Moulin J, Zbinden I, et al. (2010) Comparison of two models of intrauterine growth restriction for early catch-up growth and later development of glucose intolerance and obesity in rats. Am J Physiol Regul Integr Comp Physiol 298, R141-R146.

13. Berends LM, Fernandez-Twinn DS, Martin-Gronert MS, et al. (2013) Catch-up growth following intra-uterine growthrestriction programmes an insulin-resistant phenotype in adipose tissue. Int J Obes (Lond) 37, 1051-1057.

14. Han F, Hu L, Xuan Y, et al. (2013) Effects of high nutrient intake on the growth performance, intestinal morphology and immune function of neonatal intra-uterine growthretarded pigs. Br J Nutr 110, 1819-1827.

15. Dai Y, Thamotharan S, Garg M, et al. (2012) Superimposition of postnatal calorie restriction protects the aging male intrauterine growth-restricted offspring from metabolic maladaptations. Endocrinology 153, 4216-4226.

16. Desai M, Gayle D, Babu J, et al. (2005) Programmed obesity in intrauterine growth-restricted newborns: modulation by newborn nutrition. Am J Physiol Regul Integr Comp Physiol 288, R91-R96.

17. Guo Y, Li W \& Chen J (2010) Influence of nutrient density and lighting regime in broiler chickens: effect on antioxidant status and immune function. Br Poult Sci 51, 222-228.

18. Messaoudi I, Warner J, Fischer M, et al. (2006) Delay of T cell senescence by caloric restriction in aged long-lived nonhuman primates. Proc Natl Acad Sci U S A 103, 19448-19453.

19. Jolly CA (2004) Dietary restriction and immune function. J Nutr 134, 1853-1856.

20. Zhong X, Li W, Huang X, et al. (2012) Impairment of cellular immunity is associated with overexpression of heat shock protein 70 in neonatal pigs with intrauterine growth retardation. Cell Stress Chaperones 17, 495-505.

21. Sangild PT (2006) Gut responses to enteral nutrition in preterm infants and animals. Exp Biol Med (Maywood) 231, 1695-1711.

22. Ferenc K, Pietrzak P, Godlewski MM, et al. (2014) Intrauterine growth retarded piglet as a model for humans - studies on the perinatal development of the gut structure and function. Reprod Biol 14, 51-60.

23. Che L, Thymann T, Bering SB, et al. (2010) IUGR does not predispose to necrotizing enterocolitis or compromise postnatal intestinal adaptation in preterm pigs. Pediatr Res 67, 54-59.

24. Chen Y, Chen D, Tian G, et al. (2012) Dietary arginine supplementation alleviates immune challenge induced by Salmonella enterica serovar Choleraesuis bacterin potentially through the Toll-like receptor 4-myeloid differentiation factor 88 signalling pathway in weaned piglets. Br J Nutr 108, 1069-1076.

25. Livak KJ \& Schmittgen TD (2001) Analysis of relative gene expression data using real-time quantitative PCR and the $2^{-\Delta \Delta C_{t}}$ method. Methods 25, 402-408.

26. D'Inca R, Gras-Le Guen C, Che L, et al. (2011) Intrauterine growth restriction delays feeding-induced gut adaptation in term newborn pigs. Neonatology 99, 208-216.

27. Wang J, Chen L, Li D, et al. (2008) Intrauterine growth restriction affects the proteomes of the small intestine, liver, and skeletal muscle in newborn pigs. I Nutr $\mathbf{1 3 8}$, $60-66$.

28. Morise A, Seve B, Mace K, et al. (2011) Growth, body composition and hormonal status of growing pigs exhibiting a normal or small weight at birth and exposed to a neonatal diet enriched in proteins. Br J Nutr 105, 1471-1479.

29. Alvarenga AL, Chiarini-Garcia H, Cardeal PC, et al. (2013) Intra-uterine growth retardation affects birthweight and postnatal development in pigs, impairing muscle accretion, duodenal mucosa morphology and carcass traits. Reprod Fertil Dev 25, 387-395.

30. Monaghan P (2008) Early growth conditions, phenotypic development and environmental change. Philos Trans $R$ Soc Lond B Biol Sci 363, 1635-1645.

31. Maruyama K \& Koizumi T (2001) Superior mesenteric artery blood flow velocity in small for gestational age infants of very low birth weight during the early neonatal period. J Perinat Med 29, 64-70.

32. Xu RJ, Mellor DJ, Birtles MJ, et al. (1994) Impact of intrauterine growth retardation on the gastrointestinal tract and the pancreas in newborn pigs. J Pediatr Gastroenterol Nutr 18, 231-240.

33. Wang T, Huo YJ, Shi F, et al. (2005) Effects of intrauterine growth retardation on development of the gastrointestinal tract in neonatal pigs. Biol Neonate 88, 66-72.

34. Burrin DG, Stoll B, Chang X, et al. (2003) Parenteral nutrition results in impaired lactose digestion and hexose absorption when enteral feeding is initiated in infant pigs. Am J Clin Nutr 78, 461-470.

35. Goldberg RF, Austen WG Jr, Zhang X, et al. (2008) Intestinal alkaline phosphatase is a gut mucosal defense factor maintained by enteral nutrition. Proc Natl Acad Sci U S A 105, $3551-3556$.

36. Qiu XS, Huang TT, Shen ZY, et al. (2005) Effect of early nutrition on intestine development of intrauterine growth retardation in rats and its correlation to leptin. World $J$ Gastroenterol 11, 4419-4422.

37. Suarez-Souto MA, Lara-Padilla E, Reyna-Garfias $\mathrm{H}$, et al. (2012) Caloric restriction modifies both innate and adaptive immunity in the mouse small intestine. J Physiol Biochem 68, $163-173$

38. Fukata M, Vamadevan AS \& Abreu MT (2009) Toll-like receptors (TLRs) and Nod-like receptors (NLRs) in inflammatory disorders. Semin Immunol 21, 242-253.

39. Athman R \& Philpott D (2004) Innate immunity via Toll-like receptors and Nod proteins. Curr Opin Microbiol 7, 25-32.

40. Garg M, Thamotharan M, Dai Y, et al. (2012) Early postnatal caloric restriction protects adult male intrauterine growthrestricted offspring from obesity. Diabetes 61, 1391-1398.

41. Pham TD, MacLennan NK, Chiu CT, et al. (2003) Uteroplacental insufficiency increases apoptosis and alters $p 53$ gene methylation in the full-term IUGR rat kidney. Am J Physiol Regul Integr Comp Physiol 285, R962-R970.

42. Comans-Bitter WM, de Groot R, van den Beemd R, et al. (1997) Immunophenotyping of blood lymphocytes in childhood. Reference values for lymphocyte subpopulations. J Pediatr 130, 388-393.

43. Deng Y, Cui H, Peng X, et al. (2011) Effect of dietary vanadium on cecal tonsil $\mathrm{T}$ cell subsets and IL-2 contents in broilers. Biol Trace Elem Res 144, 647-656. 